\title{
A percepção do empoderamento feminino em relação ao exame papanicolau uma nova abordagem para prevenção do colo do útero
}

\author{
Perception of female empowerment in relation to paper examination a new \\ approach for prevention of the cervix
}

\author{
Adeânio Almeida Lima ${ }^{1}$ \\ Genilberta Meireles Biscarde ${ }^{2}$
}

\begin{abstract}
RESUMO
$\mathrm{Na}$ atenção básica de saúde, é ofertado o exame Papanicolau, que desempenha umas das funções de deteç̧ão precoce da alteração das células e são curáveis na quase totalidade dos casos. De acordo algumas literaturas e mídias informativas jornalísticas está acontecendo uma evasão de mulheres para realização do exame, pois estimam-se 16.370 casos novos de câncer do colo do útero para cada ano. Dessa forma, surge um grande paradoxo, se temos o exame Papanicolau para deteç̧ão precoce do câncer do colo de útero com estimativas de cura se descoberto em estágios iniciais, eis a inquietação, porque as mulheres não estão fazendo o exame. $\mathrm{O}$ objetivo do estudo foi analisar e identificar a percepção do empoderamento e os sentimentos das mulheres ao exame Papanicolau na atenção básica de saúde.A pesquisa possui caráter de campo, optou-se pela abordagem qualitativa e descritiva. Como campo escolhido, utilizou-se a Estratégia de Saúde da família da Santa Terezinha, localizada na cidade de Nova Soure-BA com o foco em mulheres maiores de dezoitos anos usuárias do serviço de saúde com aplicação de um questionário semi estruturado, onde ocorreu a participação de vinte e cinco mulheres. Desta forma é de extrema urgência avaliar de forma holística a situação da oferta do planejamento familiar na realização do exame Papanicolau para a integralidade da saúde da mulher com a implementação do PAISM.
\end{abstract}

PALAVRAS-CHAVE: Planejamento Familiar. Empoderamento. Preventivo.

\begin{abstract}
In primary health care, the Pap test is offered, which performs one of the functions of early detection of cell changes and is curable in almost all cases. According to some literature and news media, there is an evasion of women to undergo the exam, as it is estimated that 16,370 new cases of cervical cancer occur each year. Thus, a great paradox arises, if we have the Pap smear test for early detection of cervical cancer with estimates of cure if discovered in the early stages, this is the concern, because
\end{abstract}

\footnotetext{
${ }^{1}$ Enfermeiro; Professor; Mestre em Saúde Coletiva e Doutor em Saúde Pública. E-mail: adeaniolima@gmail.com

${ }^{2}$ Enfermeira, Especialista em Saúde Coletiva e Auditoria em Saúde. E-mail: beta_biscarde16@outlook.com
} 
women are not taking the test. The aim of the study was to analyze and identify the perception of empowerment and the feelings of women at the Pap smear in primary health care. The research has a field character, the qualitative and descriptive approach was chosen. As the chosen field, we used the Family Health Strategy of Santa Terezinha, located in the city of Nova Soure-BA with a focus on women over eighteen years of age, users of the health service, with the application of a semistructured questionnaire, where the participation of twenty-five women. Thus, it is extremely urgent to assess holistically the situation of the offer of family planning when carrying out the Pap smear for the integrality of women's health with the implementation of PAISM.

KEYWORDS: Family Planning. Empowerment. Preventive.

$* * *$

Introdução

A Estratégia de Saúde da Família foi implantada no Brasil com vistas à reorganização da atenção básica, conforme o que rege o Sistema Único de Saúde (SUS). Refere-se a um modelo assistencial mediante a implantação de equipes multiprofissionais, denominadas Equipes de Saúde da Família (ESF), responsáveis por acompanhar em uma área geográfica definida um número limitado de famílias e suas comunidades (BRASIL, 2011).

$\mathrm{Na}$ atenção básica de saúde são ofertadas várias estratégias de saúde para o cuidado e atenção ao corpo da mulher como por exemplo o planejamento familiar que engloba o exame Papanicolau, que desempenha umas das funções de deteç̧ão precoce da alteração das células e são curáveis na quase totalidade dos casos. Por isso é importante a realização periódica deste exame, mas, o que está acontecendo é uma evasão de mulheres para realização do exame, pois estimam-se 16.370 casos novos de câncer do colo do útero para cada ano do biênio 2018-2019, com um risco estimado de 15,43 casos a cada 100 mil mulheres, ocupando a terceira posição (INCA, 2018).

$\mathrm{O}$ câncer de colo do útero refere-se a uma doença, na qual ocorrem alterações intraepiteliais progressivas, as quais podem progredir para um processo invasor em 10 a 20 anos (PEREIRA et al., 2011). Entre os principais fatores de risco relacionados ao câncer de colo de útero destacam-se o início de atividade sexual precoce, relações sexuais com múltiplos parceiros sem proteção, o tabagismo, infecção pelo papilomavírus humano (HPV), além de fatores genéticos e relacionados à imunidade (INCA, 2014). 
O exame Papanicolau é a principal forma de prevenção do câncer do colo do útero. É realizado por profissionais: enfermeiros e médicos, através da coleta de amostras de células do colo do útero e do orifício uterino, com uma espátula de madeira e uma escovinha de plástico, conhecida como escova cervical, por raspagem. Estas células são dispostas em uma lâmina e fixadas, em laboratório são coradas e analisadas em microscópio (JORGE et al, 2011). Foi desenvolvido como forma preventiva, de diagnóstico e de tratamento das possíveis alterações cervicais. O principal objetivo do exame é o tratamento da infeç̧ão pelo HPV, a remoção das lesões condilomatosas, que leva a cura das pacientes na maioria dos casos.

$\mathrm{O}$ método utilizado para o rastreamento do câncer cérvico-uterino no Brasil é o exame citopatológico Papanicolau, oferecido às mulheres que tenham vida sexual ativa, mulheres em menopausa, submetidas à histerectomia parcial e gestantes. Apesar de o método diagnóstico ter sido introduzido no Brasil desde a década de 1950, estimativas revelam que $40 \%$ das mulheres brasileiras nunca foram submetidas ao exame (SANTOS et al., 2015). Este tipo de método diagnóstico deve ser realizado por mulheres de 25 a 60 anos, uma vez por ano, sendo que quando o resultado for negativo por dois anos consecutivos, devem ser realizados a cada três anos. Essa recomendação é baseada na observação da história natural do câncer cérvicouterino, que permite a deteç̧ão precoce de lesões em estágio de malignidade e o tratamento precoce, frente à lenta evolução da doença (CARVALHO; QUEIROZ, 2011).

O exame Papanicolau recebeu este nome em homenagem a seu descobridor o Dr. George Papanicolau (1883-1962). Nasceu em Coumi, uma vila grega, formou-se médico em Munique, na Alemanha; em 1910, foi para os Estados Unidos, trabalhou como assistente de laboratório e após tornou-se professor na Universidade Cornell. Ali, em 1923, ao estudar as mudanças provocadas pelos hormônios no útero, através de análises de secreções uterinas de pacientes, percebeu a presença de amostra diferenciada, com células deformadas, pertencente a uma paciente voluntária com câncer. Após repetir o exame a outras pacientes doentes, constatou que aquele tipo de análise diagnosticava tumores. Escreveu mais de 100 páginas sobre o 
assunto, sem despertar interesse, até que os resumiu a oito páginas, em 1943 o exame foi instituído, recebeu o seu nome e até hoje é o melhor método de diagnóstico do câncer do colo do útero (MEDEIROS, 2011).

O exame Papanicolau é considerado um método simples, eficaz, de baixo custo, rápido e seguro utilizado para a detecção de alterações da cérvice uterina, a partir da presença de descamação de células do epitélio para o rastreamento do câncer cérvico-uterino, realizado em nível ambulatorial. Apesar da importância do exame de Papanicolau, diversos estudos demonstram que existe elevada incidência de falta de adesão do público feminino ao preventivo, oriundos de fatores como desconhecimento do câncer uterino e do exame Papanicolau e o modo como é realizado.

Um dos grandes desafios do Brasil atualmente consiste na busca pela ampliação dos programas de prevenção e detecção precoce. Devido aos elevados índices de mortalidade mesmo com a inserção de campanhas de prevenção, o câncer cérvico-uterino tem sido considerado problema de saúde pública, entretanto a prevenção quando preconizada do modo adequado possui capacidade de fornecimento de um dos mais altos potenciais de cura (DIAS et al., 2014).

Dessa forma, nos surge um grande paradoxo, se temos o exame Papanicolau para deteç̧ão precoce do câncer do colo de útero com estimativas de cura se descoberto em estágios iniciais e o exame preventivo é gratuito ofertado pela atenção básica de saúde nas estratégias de saúde do familiar, eis a inquietação, porque as mulheres não estão fazendo o exame? Para tanto, se propõe responder a seguinte questão norteadora: de que maneira as políticas públicas de saúde coletiva podem contribuir para o empoderamento feminino para a realização do exame Papanicolau? Pretende-se em especial, na assistência integral a saúde da mulher voltada ao planejamento familiar, no qual na maioria das vezes o exame pode ser visto como algo constrangedor, que gera desconforto e dores entre outros fatores que serão discorridos no decorrer da pesquisa que provocam a grande ausência da mulher.

Portanto essa pesquisa foi baseada na questão da extrema urgência de avaliar de forma holística a situação da oferta do planejamento familiar na realização do exame Papanicolau para a integralidade da saúde da mulher 
com a implementação do PAISM. O objetivo do estudo foi analisar e identificar a percepção do empoderamento e os sentimentos das mulheres no contexto do planejamento familiar em relação ao exame Papanicolau na atenção básica de saúde.

A pesquisa possui caráter de campo, optou-se pela abordagem descritiva. Como campo escolhido, utilizou-se a Estratégia de Saúde da família da Santa Terezinha, localizada na cidade de Nova Soure-BA com o foco em mulheres maiores de dezoitos anos, com aplicação de um questionário semiestruturado com seis questões de múltipla escolha, onde ocorreu a participação de vinte e cinco mulheres, cadastradas na Unidade Básica de Saúde Santa Terezinha, com noventa e nove por cento da raça parda, mais de dois filhos e a maioria são solteiras. Com relação ao nível de escolaridade, constata-se que há um índice elevado ao grau fundamental e onze têm profissão de lavradoras. Assim, o contexto onde as entrevistadas estão inseridas tem forte repercussão na sua forma e organização de vida social.

\section{Desenvolvimento}

A despeito de iniciativas que datam de 1940, as quais ofereceram ao país métodos de diagnóstico e tratamento do câncer do colo do útero por meio de citologia e colposcopia, um grande impulso na prevenção do câncer se deu com a criação do Sistema único de saúde (SUS). Uma vez apoiado em princípios de promoção da saúde e tendo o Instituto Nacional de Câncer (INCA) como responsável em formular políticas de prevenção ao câncer, alguns avanços em termos de políticas públicas na busca pela diminuição da incidência de câncer de colo uterino vêm se efetivando no país.

No Brasil, a saúde da mulher foi incorporada às políticas nacionais de saúde nas primeiras décadas do século XX. Ao longo da década de 1980, o Ministério da Saúde propôs diretrizes para a humanização e qualidade no atendimento, implementando programas voltados à saúde da mulher, destacando-se o Programa de Assistência Integral à Saúde da Mulher (PAISM). A partir desse programa e da necessidade de melhorar a atenção, 
com base na promoção da saúde e nos princípios do Sistema Único de Saúde universalidade, equidade e integração, foram desenvolvidos outros programas no campo dos direitos sexuais, reprodutivos e entre outros (LICHAND et, al., 2012).

A política Nacional de Atenção Integral à Saúde da Mulher considera, desde a luta pela implantação do Programa de Assistência Integral à Saúde da Mulher (PAISM), quando o movimento feminista e o processo de redemocratização do País desempenharam um papel decisivo para a sua concepção e formulação, até a atualidade quando se amplia e consolida o Estado democrático no Brasil, incluindo na agenda nacional a saúde como direito e cidadania. É importante ressaltar que o PAISM nasce antes da implantação do Sistema Único de Saúde (SUS) e antes da promulgação da Carta Magna. É, portanto, pioneiro no uso do termo integralidade da saúde na política pública, cujo significado é construído e proposto pelos movimentos sociais feministas.

As medidas preventivas especificamente dirigidas ao câncer do colo do útero foram fortalecidas no início da década de 80, com a criação do Programa de Assistência Integral à Saúde da Mulher (PAISM) que é um programa voltado para a assistência da mulher, nos seus aspectos clínico- ginecológico, incluindo o planejamento familiar, climatério, controle e prevenção das IST's, do câncer de mama e câncer cérvico-uterino.

Para Formiga (2007), O PAISM consiste em uma das mais importantes políticas públicas na área da saúde, por estabelecer em suas linhas de ações e estratégias, um modelo assistencial integral e equitativo.Posteriormente, duas iniciativas governamentais foram criadas e preconizam a prevenção e controle deste câncer: o Programa Viva Mulher e o Pacto pela Saúde 2006 Consolidação do SUS. Tais iniciativas fortalecem as ações da Estratégia Saúde da Família (ESF), lançada pelo Ministério da Saúde (MS) para reorientar o modelo assistencial do SUS a partir da atenção básica (OLIVEIRA et al., 2010).

Devido à importância deste tipo de câncer, tendo em vista seu elevado número de incidência, no ano de 1998 o Ministério da Saúde instituiu o Programa Nacional de Combate ao Câncer de Colo do Útero através da 
Portaria GM/MS n ${ }^{\circ}$ 3040/9810, que contava com a adoção de estratégias para estruturação da rede assistencial, desenvolvimento do sistema de informações, estabelecimento de mecanismos para mobilização e captação de mulheres, assim como definição das competências nos três níveis de governo. Após a transferência da coordenação do programa para o Instituto Nacional do Câncer (Portaria GM/MS nº 788/99), o ministério da saúde criou o Sistema de Informação do Câncer do Colo do Útero (Siscolo), um software utilizado para o fornecimento de dados sobre identificação da paciente, informações demográficas, epidemiológicas e dos exames citopatológico e histopatológicos realizados no SUS (BRASIL, 2010).

O Siscolo aprimorou-se ao longo dos anos e, atualmente, consiste numa ferramenta fundamental para organização das ações de rastreamento, informações gerenciais e faturamento dos exames. O Sistema permite ainda obter o boletim de produção ambulatorial individualizado, registra informações sobre as condutas diagnósticas e terapêuticas relativas aos exames positivos/ alterados, selecionar amostras para monitoramento externo da qualidade dos exames e coleta dados para construção de indicadores, auxiliar na conferência dos valores de exames pagos em relação aos dados dos exames apresentados; apoia rede de gerenciamento no acompanhamento da evolução do programa e dissemina informações em saúde para gestão e controle social do SUS, bem como para apoio à pesquisa em saúde (BRASIL, 2011).

No ano de 2004, foi criada a Política Nacional de Atenção à Saúde da Mulher (PNAISM), envolvendo ações educativas no sentido mais amplo, contemplando ações de promoção a saúde, prevenção, e tratamento dos principais agravos a saúde que afetam as mulheres, como câncer de colo uterino, câncer de mama, gravidez de alto risco, violência contra a mulher, dentre outros (PAZ; SALVARO, 2011).

De acordo com os autores anteriormente citados, é de grande importância a mobilização de mulheres e a conscientização destas quanto a efetivação do exame citopatológico, visando assim o rastreamento de possíveis ocorrências do câncer cérvico-uterino. O programa de atenção à saúde da mulher está voltado para a prevenção, no entanto é necessário que haja 
compromisso por parte das mulheres em comparecer aos serviços de saúde, para que sejam implantadas as ações destinadas ao cuidado com a saúde da mulher. É uma nova tática de trabalho, voltada para a integralidade na atenção e prática educativa, que visa apropriar-se a clientela de conhecimentos necessários para a saúde.

Existe uma ambiguidade de sentimentos em relação a execução do exame cito-patológico que se relaciona ao medo. $\mathrm{O}$ medo da doença, da dor e da morte leva as mulheres ao cuidado com o corpo, e é este medo que as move ao serviço de saúde em busca de prevenção (PAULA E MADEIRA, 2003).

A vergonha de se submeter ao exame Papanicolau foi um dos sentimentos mais recorrentes relatados pelas mulheres participantes da pesquisa, assim como em outros estudos (MENDONÇA, 2011; WILIANS; AMOATENG, 2012). Portanto, à não aceitação decorrente do processo psicológico de ser flagrado fora dos padrões aceitos e valorizados pela sociedade, a exposição do corpo no momento do procedimento remete a questões referentes à sexualidade, podendo aflorar sentimentos negativos de bloqueio e conflito para algumas mulheres. (DUAVY et al., 2007). E como pode ser notado no gráfico 1 abaixo o relato sobre o sentimento de vergonha prevalece na pesquisa de campo executadae as mulheres que não sentiam vergonha, deixou claro que o exame deveria ser realizado por um profissional de saúde, do sexo feminino, nesse caso uma enfermeira.

$\mathrm{Na}$ indagação sobre o planejamento familiar na consulta de enfermagem foi constatado sobre a realização do exame ginecológico, como mostra no gráfico 1, que treze mulheres se sentem muito envergonhas e dez mulheres confirmaram ficarem neutra ou à vontade se for com enfermeira do sexo feminino. De acordo com Ressel et al(2013), estudo aponta que 39,3\% das mulheres indicam a vergonha como principal sentimento desafiador para a realização do exame, enquanto para $21,4 \%$ das mulheres o medo é o principal sentimento que dificulta a realização do exame. Outros sentimentos vivenciados também são a ansiedade, a tensão e violência, além da insegurança e a invasão de privacidade relatada pelas mulheres como problemas que antecedem a realização do exame, por isso a importância de os profissionais realizarem anamnese e escuta sensível. 


\section{Gráfico 1: Sentimentos expressados pelas mulheres ao realizarem o exame preventivo}

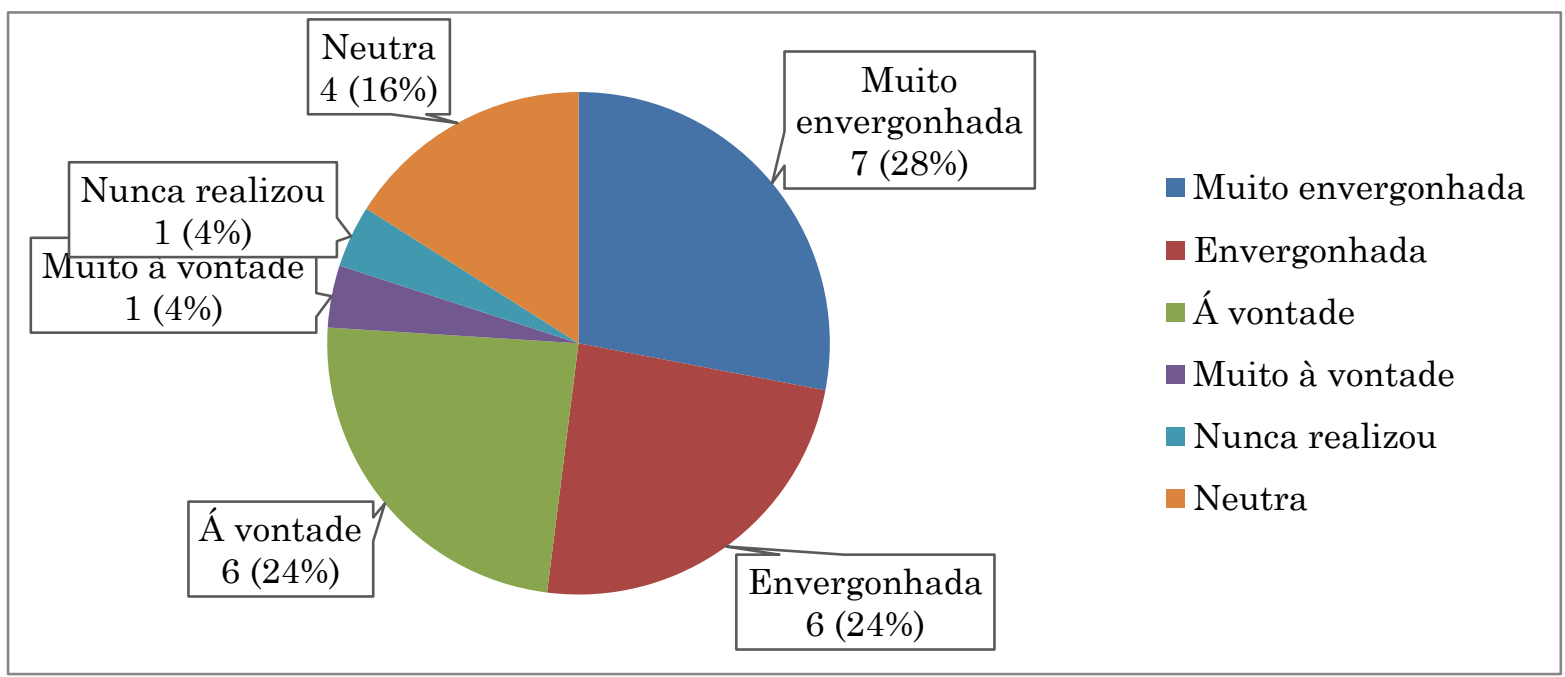

Fonte: Autoria própria

E estas resistências são geralmente externadas e um outro fator relacionado a experiências restritivas no âmbito da sexualidade, falta de informação acerca da anato-mofisiologia feminina, conhecimento deficitário sobre o cuidado acerca da saúde sexual, concepções do câncer como sinônimo de perda de controle da sua própria vida e de proximidade da morte, experiências de violência, falta de acesso e falta de comunicação/explicação acerca do exame nos serviços de saúde, são alguns dos fatores que contribuem para a externalização de sentimentos negativos como vergonha, medo e constrangimento por parte das mulheres em relação ao exame Papanicolau (OLIVEIRA; PINTO, 2007; RICO; IRIART, 2013).

É visto que a mulher, durante o exame, é mais do que um colo uterino, ela é também um corpo que tem sentimentos, que pulsa e vibra, que interage com o mundo, com o outro e consigo mesmo; que deixa transparecer por gestos, expressões, olhares, palavras e silêncio, como experiência esse momento (PAULA E MADEIRA, 2003, p. 95). A exposição em que a mulher é submetida no momento da realização do exame Papanicolau evidencia diversos sentimentos e muitos são negativos.

Pelloso e colaboradores (2004) atentam para o fato de que, no momento do exame, os profissionais parecem não compreender que a mulher se encontra em situação de quase abandono e, assim, lidam com o evento de 
forma corriqueira e sem importância. Ressaltam ainda que a relação da postura do profissional, muitas vezes, pode caracterizar uma postura de submissão assumida pelas mulheres, e esta relação de submissão e dominação pode ser um empecilho para uma maior cobertura dos exames.

Para a construção do conhecimento das mulheres sobre o exame citopatológico, devemos considerar que a compreensão e a utilização das informações contemplem as características e o contexto em que as usuárias estão inseridas. Pois muitas vezes é usada uma linguagem pouco compreensível ou até mesmo a comunicação é restringida em dados objetivos da mulher em detrimento do subjetivo, de seus sentimentos e expectativas para aquele momento. Muitas vezes, a falta de conhecimento adequado sobre este exame e sua importância, pelas mulheres, podem constituir uma barreira, tanto para os serviços de saúde, quanto para as usuárias que o utilizam (RESSEL, 2013).

E aos profissionais de saúde, que é necessário aprender a lidar de uma maneira diferente com o corpo do outro e com sua sexualidade, uma vez que na prestação do cuidado, os profissionais renegam o constrangimento e a forma como se construiu os significados em relação ao corpo, a intimidade e sexualidade dos sujeitos cuidados. $\mathrm{O}$ investimento de orientações e esclarecimentos oportuniza que as mulheres voltem seus olhares, com maior compromisso, para questões relacionadas ao autocuidado, e exercitem seu papel de protagonistas na preservação de sua saúde (RESSEL, 2013).

O profissional de saúde em especial o enfermeiro, a expandir atividades didáticas, abrange uma atribuição essencial na prevenção e promoção da saúde das pessoas. Á vista disso nesse discernimento, ao separar-se do padrão biomédico, com a finalidade de semear o conhecimento das mulheres e a indução do zelo em si. Esse apetrecho, além de aconchegar o enfermeiro da paciente/cliente, concede dar voz à mulher, beneficiando sua fala, sentimentos e instrução a respeito do seu próprio corpo (SILVA et al, 2008).

A conduta do profissional de saúde é imprescindível para aceitação e demanda de dedicação pelas mulheres. Com atuação de respeito, companheirismo, estabelece-se conexão, ligação de confiabilidade, que fortalece a prudência, impulsiona a plenitude do mesmo, o que vai refletir na 
idealização de uma associação e cuidado acolhedor, apoiante e maleável. Dessa maneira, as assimilações das mulheres em correlação ao seu corpo e aos fenômenos que circundam a sexualidade exercer de forma a experimentar os cenários de cuidado (OLIVEIRA, 2007).

A relação entre o profissional e o sujeito do cuidado deve ser entendida desde o início como uma forma de intervenção e/ou tratamento e não apenas como um mero instrumento, mostrar a coleta de informações necessárias a um diagnóstico. Com isso, a enfermagem pode contribuir para a satisfação da mulher, a decisão compartilhada no planejamento das ações de saúde. No processo de cuidar, a enfermagem exerce o comportamento afetivo encoraja a mulher, demonstra preocupação e segurança, olha nos olhos, chamar pelo seu nome e entre outros; Um exemplo é para a realização do exame ginecológico para evitar o pavor é a entrega do espéculo vaginal na mão da mulher, sendo um gesto que oportuniza a mulher conhecer, ver e sentir, ou seja, devem existir alguns recursos pessoais que possam apoiar o processo de empoderamento.

Para a construção de um vínculo entre a enfermeira e a paciente/cliente, deve-se ser capaz de identificar as pistas não expressas verbalmente e identificar a comunicação não verbal, seja por gestos, ou outros mecanismos. Diante desta nova perspectiva, os profissionais são desafiados a modificar a forma de aproximação e passar a ver o corpo como ser-no-mundo. A frente dessa mudança, pode-se colocar em prática a decisão compartilhada, onde o atendimento não está baseado unicamente no saber do profissional. Este deve considerar outros conhecimentos como possibilidade.

A enfermeira deve priorizar o conhecimento do próprio corpo como condição fundamental para o cuidado humanizado, reconhecendo o autoexame das mamas como uma estratégia importante para 0 empoderamento feminino. (SALOMÃO \& AZEVEDO, 2010). Podemos correlacionar com o contexto mencionado da figura 1 , com o título por que não conhecemos nosso corpo? Fazemo-nos a pergunta, porque os profissionais de saúde, na maioria das vezes não conseguem ajudar as pacientes/clientes a conhecer a sua própria anatomia e sua sexualidade. 
A enfermeira pode reconhecer que a metodologia de cuidar não é de controlar. Como por exemplo, eliminar a mesa para a entrevista é uma estratégia interessante para melhorar o acolhimento à mulher. Assim, o profissional elimina não apenas uma barreira física, mas também uma barreira simbólica, pelo que está representa no espaço da comunicação do profissional com a mulher. (VARGENS, 2007) A prática do exame ginecológico, com autonomia da mulher que é uma metodologia inovadora na forma de oferecer serviços de saúde, fomenta a criatividade das pessoas e seu sentido crítico em relação às práticas existentes. Também ajuda a mulher a pensar e a aprofundar o conhecimento e a reflexão sobre si mesma (ARAUJO, 2000).

Todavia muitas vezes, a relação, o diálogo e a escuta são colocados em segundo plano, para dar lugar a um processo de trabalho centrado no formulário, protocolos, procedimentos como se estes fossem um fim em si mesmo. (MERHY, 2002). Dessa maneira, conforme pesquisa feita por Coelho et al (2009) no pertinente à resolutividade das ações em saúde, as (os) participantes da pesquisa deram relevância à contracepção como aspecto que exemplifica a negação dos direitos sexuais e reprodutivos das mulheres. Segundo a rotina do serviço em que foi realizada a pesquisa, o atendimento à contracepção é feito com agendamento prévio para avaliação clínica, variável segundo o método escolhido.

Segundo Silva et al (2008), diz que o tabu mais frequente entre as depoentes surge com a dificuldade na hora da realização do exame, pelo fato de algumas mulheres ainda terem receio de sentir dor, medo ou vergonha, ou seja, foi constatado a existência de fatores que contribuíam para recusa das depoentes em se submeter ao exame Papanicolau, tais como: a desinformação, a falta do costume de se prevenir da doença, a dificuldade de acesso às unidades municipais de saúde e a proibição de alguns maridos. E que muitos comportamentos em algumas depoentes foram influenciados pelo grupo social ao qual pertenciam no que diz respeito à questão da vergonha e do medo de realizar o exame, ou seja, elas já foram com uma ideia prévia de que seria um procedimento que causaria dor e constrangimento. 
A vergonha e o pudor também podem ser expressos pelas mulheres como uma 369 sensação de impotência, desproteção e falta de domínio sobre o próprio corpo, os quais são proporcionados através da posição ginecológica indispensável para a realização do exame (FERREIRA, 2009).

Observou-se, ainda, que o sentimento de vergonha apresenta grande impacto se o exame tiver que ser realizado por um profissional do sexo masculino, diferentemente do que se espera quando o examinador é do sexo feminino. Tal posição pode ser explicada por uma possível conotação de cumplicidade entre seres semelhantes, portadores de uma mesma anatomia e talvez com as mesmas vivências de privação do corpo, de quem se pode esperar compreensão (JORGE et al., 2011; SOUSA et al., 2008).

O sentimento de vergonha corresponde, portanto, à não aceitação decorrente do processo psicológico de ser flagrado fora dos padrões aceitos e valorizados pela sociedade, onde o outro é tido como avaliador numa posição de juízo alheio (DUAVY et al., 2007). Para alguns profissionais de saúde, a não realização do exame Papanicolau perpassa por questões também relacionadas ao pudor, o que reforça a forte presença dessa barreira no âmbito das mulheres.

Souto (2008) afirma que o corpo feminino é um lócus privilegiado de instrumentação e de submissão e opressão. Nas dimensões do cuidado com a saúde da mulher também se expressam intervenções voltadas para corpo, definidas pelo papel que a sociedade de forma hegemônica lhe impõe, como mãe e reprodutora. É sob esse olhar que institucionalizaram os primeiros cuidados em saúde da mulher: saúde materna e do ciclo gravídico-puerperal, no qual, sua a sexualidade da mulher também está restrita à sua condição de reprodução.

O papel da mulher dentro das políticas públicas não favorece o empoderamento feminino, segundo o seu percurso histórico, que é de luta, existem marcas na conquista da sua cidadania, principalmente sobre a necessidade de equidade de gênero que é ocultado, pois o papel imposto pela sociedade para mulher é de um ser apenas reprodutor, e as políticas de saúde favorecem essa tese, vinculando a saúde da mulher como mulher-mãe, 
materno-infantil e o descaso do poder público em relação à violência contra mulheres.

A mulher, a partir de então, é vista em sua integralidade, como sujeito autônomo e participativo no processo de decisão para a formulação de políticas públicas, tendo em vista que à medida que a mulher é incluída nesse processo, há garantia do atendimento de suas reais necessidades aumentando a qualidade da assistência (FREITAS, 2009).

Notou-se que ao indagar no questionário sobre como aconteceu o primeiro relacionamento sexual das mulheres constatamos os seguintes resultados como demostrados no gráfico 5 abaixo, quinze mulheres relataram ter sido por prazer, seis mulheres falaram que foi por curiosidade, uma mulher disse que foi por convívio com os amigos, duas mulheres responderam que foi pressão do parceiro e uma mulher respondeu que foi por amor.

\section{Gráfico 2: Como aconteceu o primeiro relacionamento sexual das mulheres}

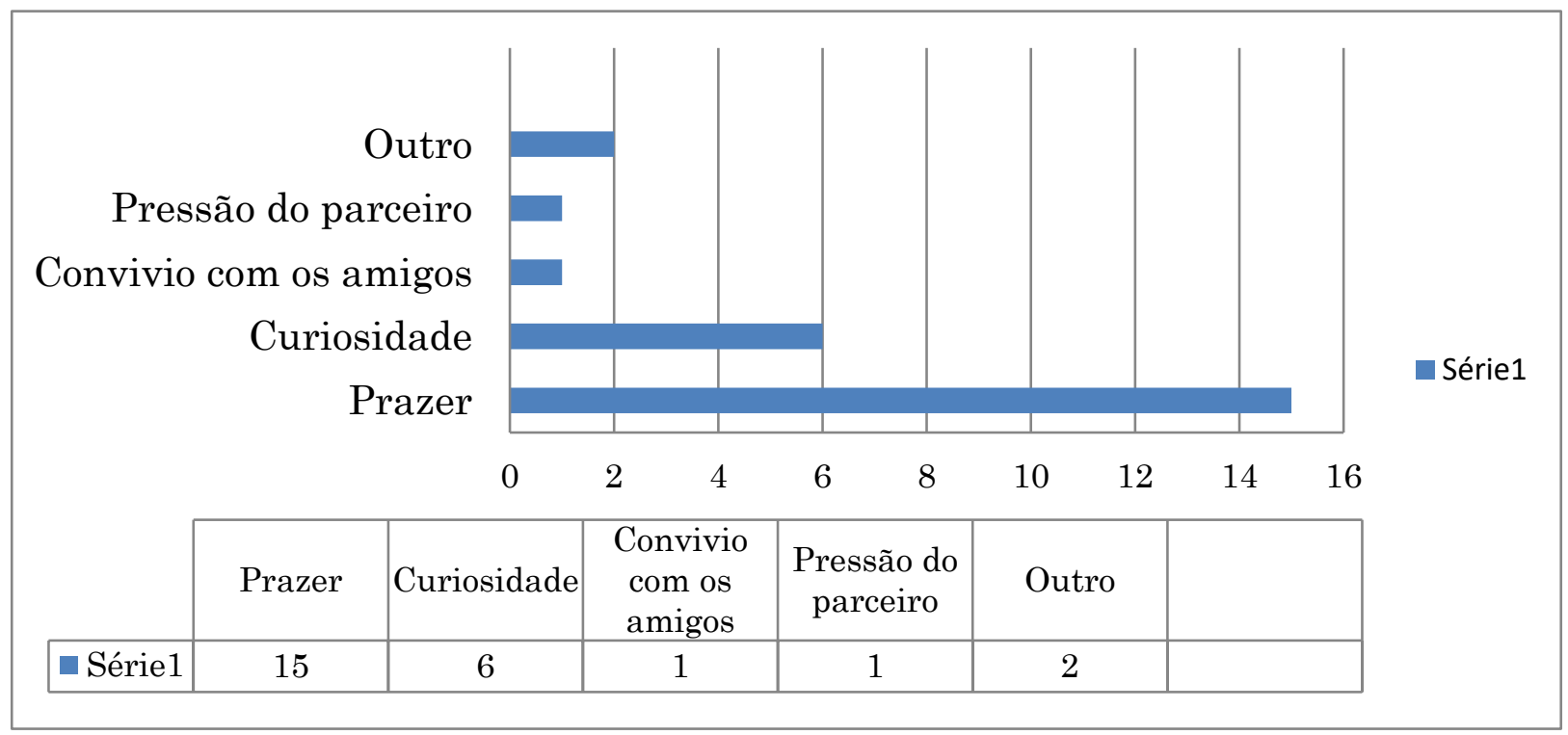

Fonte: Autoria própria

Mesmo que a grande parte, das mulheres afirme que seu primeiro contato sexual foi por prazer e com uma figura masculina, nós traz a inquietação sobre instruções e prevenção para o primeiro ato sexual, pois até o momento foi notado que a grande busca das mulheres na unidade básica é 
no contexto mulher-mãe, e nos dados da pesquisas todas as mulheres tiveram relação sexual com menos de dezoito anos e possuem um grande quantitativo de filhos que não foram planejados, então percebemos que é preciso proporcionar às usuárias a possibilidade de iniciar sua trajetória sexual sem risco de gravidez imprevista não integra as prioridades na organização dos serviços. Esses sentimentos estão relacionados a experiências vivenciadas durante suas vidas, em que foram cercadas de restrições, ao não conhecimento de sua anatomia e fisiologia, à cultura, à sociedade, ao preconceito de gêneros.

Segundo Heilbom et al(2009), menciona queos serviços de saúde privilegiam assistência às mulheres em trajetória reprodutiva; há necessidade de atenção às mulheres adultas não grávidas e adolescentes, além do fortalecimento do trabalho educativo na ESF. Salienta-se que o planejamento reprodutivo ainda está organizado segundo a lógica que privilegia a díade materno-infantil. Não há esforço na mesma magnitude em relação às mulheres que ainda não pariram, não desejem parir ou tenham dificuldades para engravidar. Os serviços de saúde terminam priorizando o atendimento em contracepção a partir do momento em que a mulher já iniciou sua trajetória reprodutiva.

No tangente a decisão de ter filhos e a quantidade foi observada que doze mulheres não fizeram planejamento para a geração dos filhos, segundo as mesmas "foi acidente", já onze mulheres afirmaram ter decidido ter filhos e duas das entrevistadas não possuem filhos.Podemos pronunciar que a gravidez não foi idealizada pela quantidade significativa observada e por outro levantamento sobre o uso do preservativo e método contraceptivo, dentro do relacionamento, ou da vida sexual ativa em que, quatro mulheres afirmaram que eram obrigadas ao uso pelo parceiro e vinte e uma das mulheres responderam que não. Assim fica claro o quanto as mulheres precisam de autonomia e conhecer o seu próprio corpo e da necessidade de planejamento familiar adequado, pois dessas vinte e cinco, das mulheres abordadas apenas seis são casadas, é possível afirmar que ocorre uma fragilidade na busca e no sistema de educação e saúde.

No Brasil, país caracterizado como terceiro mundo ocorre uma grande desigualdade social, econômica, onde pessoas passam por situações 
extremamente injustas e desumanas no que diz respeitos aos seus direitos e interesses, principalmente as mulheres pobres e analfabetas, vítimas do descaso do governo, como referenciado nas mídias televisivas, onde estudiosos apontam que diversas mulheres vivem em condições de extrema pobreza, a elas cabem somente deveres e proibições.

O acesso e a informação dos métodos não são suficientes para a segurança de uma gravidez indesejada. Faz-se necessário que todos os profissionais de saúde, em especial da Enfermagem, considerem a individualidade de cada mulher, dado que cada uma possui sua história de vida, condições econômicas e bens sociais específicos, ao viver em uma sociedade politicamente organizada como o Brasil (FARIA PENAFORTE et al, 2010).

A primeira causa de diferenciação da mulher na sociedade é o fato de ela gerar e amamentar os filhos, além de ser considerada fisicamente mais fraca que os homens. Essa diferenciação fisiológica gerou uma divisão das tarefas em que às mulheres cabiam todos os cuidados com a manutenção da família, ou seja, além de procriarem, cuidarem dos filhos, da casa e das roupas, as mulheres também produziam alimentos, cuidavam da horta, do pomar, realizavam partos e fabricavam remédios naturais (SULLEROT, 1988).

A literatura é pródiga em sinalizar que a desinformação, o conhecimento errôneo ou insuficiente constitui barreiras à realização de medidas preventivas para o câncer de colo de útero, como a realização do Papanicolau (JORGE et al., 2011; MENDONÇA et al., 2011; OLIVEIRA; PINTO, 2007; RICO; IRIART, 2013; SOUSA et al., 2008). O baixo nível socioeconômico das mulheres entrevistadas também contribui para tal situação, pois à medida que diminui o nível socioeconômico, aumenta significativamente a prevalência de mulheres sem cobertura pelo exame Papanicolau (JORGE et al., 2011; LUCENA, 2011).

$\mathrm{Na}$ questão sobre o uso da camisinha feminina para as usuárias da unidade, como observado no gráfico 3, captamos que vinte e três mulheres não conhecem a camisinha feminina e duas mulheres possuem conhecimento, foi questionado o porquê de não saber sobre o método de proteção e no qual foi 
escrito por elas que nunca tiveram a oportunidade de ver, que não sabem como usar e outras que não possuíam interesse, referindo - "é feia”, "é estranha", "parece uma sacola", desse modo é destacado que as mulheres estão desatentas quanto ao uso da camisinha feminina, que pode ser caraterizada como falta de conhecer seu próprio corpo.

\section{Gráfico 3: O uso da camisinha feminina}

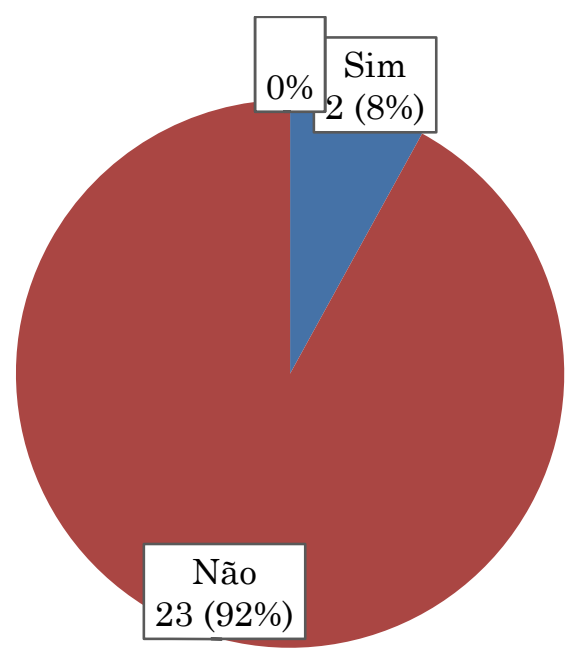

Fonte: Autoria própria

Entretanto o uso da camisinha é a única maneira eficaz de prevenção das IST's. No entanto, seu uso nem sempre está relacionado à prevenção de doenças e infecções, mas sim à contracepção (Fernandes et al, 2000). No que diz respeito à camisinha feminina, dados da Pesquisa Nacional de Demografia e Saúde da Criança e da Mulher (PNDS) 2006, revelam que, apesar de 91\% do total de mulheres conhecerem ou já terem ouvido falar do método, apenas $3 \%$ já usaram alguma vez e o uso atual é nulo (BRASIL, 2008).

Miranda-Ribeiro et.al. (2008), ressaltam que a dificuldade de incorporação da ideia de prevenção, "pois o verbo amar, ao ser conjugado no feminino, adquire um forte sentido de abnegação, de negação de si mesma em função do outro e a prevenção implica interpor um objeto ou uma racionalidade ao desejo..." É notável sobre a camisinha feminina que as mulheres não costumam utilizá-la, independente da opinião do parceiro, se a camisinha feminina não faz parte do cotidiano e seu uso, conforme dados encontrados na entrevista, podemos ressaltar que não é estimulado pelos profissionais da área de saúde, as pretensas vantagens de sua adoção 
simplesmente não se efetivam, ou seja, o papel da camisinha feminina enquanto alternativa que, na prática, promova o empoderamento da mulher dentro do processo de negociação e proteção.

Assim ocorre uma necessidade de trabalhar com as mulheres em idade reprodutiva e também com os companheiros sobre planejamento familiar em atividades com grupos de discussão, salas de espera e orientações individuais, durante as consultas de Enfermagem.

Silva et al(2008), ressaltam a necessidade de desmistificar o exame Papanicolau, eliminando a vergonha e o medo que muitas mulheres ainda têm ao procurar o serviço de saúde. Essa atitude é uma questão cultural, pois vivemos em uma sociedade patriarcal em que a mulher durante muito tempo foi reprimida pela figura masculina, primeiro pela dominação do pai, depois pela do marido, que muitas vezes não incentiva sua esposa, sua irmã e sua mãe a realizarem seus exames, externando assim uma atitude de domínio.

É notório que as mulheres crescem num seio familiar restrito ao conhecimento sobre seu corpo e sexualidade porque a figura masculina do pai oculta essas informações, que pode ser caracterizado com um tabu ao corpo feminino e nos remota a construção ideológica do corriqueiro adágio que meninas só podem andar com meninas e que são as eternas princesas dos pais e que os mesmo não conseguem ver as filhas como mulheres com sua sexualidade, a mulher deve ser concebida como um ser integral, biológico e psicossocial, analisar a mulher inteira como um ser que sente, pensa, que deve ser vista integralmente e não apenas pelo sintoma mais evidente.

No dizer de Silva et. al.(2008), o sistema de saúde muitas vezes considera a mulher importante apenas no que diz respeito à função reprodutora e a realização dos programas de prevenção do câncer de colo uterino na educação pública torna-se exemplo de um esforço organizado para realizar diagnósticos precoces, por meio de uma técnica de educação em massa. 
Uma mulher dentro dessa conjuntura familiar não terá instrução oucuriosidade de conhecer seu próprio corpo, pois poderá ficar com receio de estar pecando segundo as normas das doutrinas religiosas, que tem a mulher como serreprodutor como foi discutido no decorrer do referencial teórico. Ao ir para frente do espelho nua e tocar sua vagina para conhecê-la e senti-la não é algo praticado entre as mulheres usuárias da pesquisa, como mostra no gráfico 4 que pode ser constatado que quinze mulheres responderam nunca ter tocado ou olhado sua vagina na frente do espelho e dez mulheres falaram ter feito o conhecimento da sua vagina, mas, quando indagado a seguinte questão "o canal que vocês fazem urina (diurese) é o mesmo onde passa o bebê e sai à menstruação?", o resultado das respostas é que elas entendem ter apenas um orifício na vulva, então compreendemos que é preciso um conhecimento maior sobre a anatomia feminina.

\section{Gráfico 4: Olhou a vagina e já se tocou na frente do espelho}

Respoderam não $15(60 \%)$

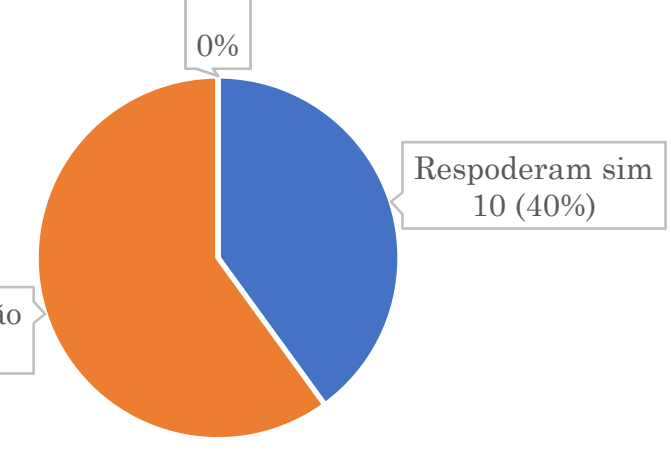

- Respoderam sim $\quad$ Respoderam não

Fonte: Autoria própria

Santos (2003, p.301; 314), nos diz que "as relações familiares estão dominadas por uma forma de poder, o patriarcado, que está na origem da discriminação sexual de que são vítimas as mulheres". O autor fala que apesar dessas descriminações não estarem presentes apenas no espaço-tempo doméstico já que as mulheres são discriminadas também nas relações de trabalho e nos outros espaços em que se relaciona, o patriarcado familiar é a matriz dessas discriminações, ainda que em articulação com outros fatores. 
Ainda segundo esse autor, é a ideologia do patriarcado que tende a influenciar a subordinação da mulher na sociedade.

Considerações finais

As políticas de atenção à saúde da mulher formuladas nacionalmente através de amplas e complexas discussões trouxeram contribuições imprescindíveis para o processo de transformação sobre o paradigma da saúde da mulher. Então, é preciso que os significados do corpo, da sexualidade, do feminino e do "ser mulher" sejam relevantes. É preciso perceber que a mulher, quando submetida ao exame, leva consigo mais do que um corpo. Ela leva sua história, seus valores, seus sentimentos, suas angústias, suas vivências, suas carências, seus medos, seu conhecimento e o seu desconhecimento.

Conforme percebeu-se, apesar das mulheres frequentarem assiduamente os serviços de saúde, elas o fazem, sobretudo, para o cuidado com filhos e familiares. O cuidado da própria saúde vem em plano secundário. É preciso modificar esta cultura. Cabe aos serviços aproveitar todas as chances de envolver a mulher na promoção da sua saúde. Pois a compreensão do dos papeis sexuais de homens e mulheres são concebidos como construções históricas diferenciadas e ao incorporar a dimensão das relações de poder entre homens e mulheres, possibilita a percepção dos poderes na esfera feminina, permitidos por uma situação de sujeição, que devem ser entendidos como contra-poderes, até porque numa sociedade impregnada por códigos e valores que limitam comportamentos, principalmente no campo da sexualidade, o papel da mulher na maioria das vezes é visto a mulher com mãe reprodutora e que sua integralidade fica em segundo plano, a mulhermãe se preocupa com a saúde da família e esquece da própria saúde.

A pesquisa ressalta a necessidade de um aprofundamento acerca do tema para uma melhor preparação dos profissionais de saúde, independentemente do nível de atenção prestada, através dos programas voltados a promoção à saúde. Além disso, desenvolver ações voltadas a uma assistência de qualidade e humanizada, garantindo o respeito à saúde da mulher e seus familiares e a inserção da mesma na comunidade, de forma a 
implementar estratégias que visem ampliar e facilitar o acesso das mulheres como: permitir o atendimento sem agendamento, diversidade no horário e dia de atendimento (incluindo horário noturno e finais de semana) e busca ativa das mulheres.

Desta forma, é necessário que haja uma desconstrução, dentro das políticas públicas de saúde, da visão de mulher como segundo sexo e não apenas como mulher-mãe reprodutora. Portanto é de extrema urgência avaliar de forma holística a situação da oferta do planejamento familiar na realização do exame Papanicolau para a integralidade da saúde da mulher com a implementação do PAISM.

\section{Referências}

ARAUJO, Maria José de Oliveira et al. O papel das práticas educativas: como a questão educativa é encerada no Coletivo Feminista Sexualidade e Saúde. In: Saúde das mulheres: experiência e prática do coletivo feminista sexualidade e saúde. Coletivo Feminista Sexualidade Saúde, 2000. Disponível em: $<$ http://www.scielo.br/pdf/ean/v19n4/1414-8145-ean-19-04-0685.pdf>. Acessado em: 14 ab. 2021.

BRASIL. Ministério da Saúde. Secretaria de Atenção à Saúde. Departamento de Ações Programáticas Estratégicas. Política nacional de atenção integral à saúde da mulher. Brasília: Ministério da Saúde; 2011. Disponível em: $<$ http://bvsms.saude.gov.br/bvs/publicacoes/politica_nacional_mulher_principios_di retrizes.pdf>. Acessado em: 14 abr. 2021.

Ministério da Saúde. Assistência integral à saúde da mulher: bases da ação programática. Brasília: Ministério da Saúde, 1996. Disponível em: <http://bvsms.saude.gov.br/bvs/publicacoes/cd03_05.pdf>. Acesso em: 14 abril 2021.

BRASIL, PAISM: um marco na abordagem da saúde reprodutiva no Brasil. Cad. Saúde Pública. Rio de Janeiro, v. 14, p. 25-32, 1998. Suplemento 1. Disponível em: $<$ https://www.nescon.medicina.ufmg.br/biblioteca/imagem/0734.pdf >. Acesso em: 14 abr. 2021.

COSTA, Ana Maria; AQUINO, Estela Leão; TAJER, Debora. Saúde da mulher na reforma sanitária brasileira. In: Saúde, equidade e gênero: um desafio para as políticas públicas. UnB, 2006. Disponível em: $<$ https://www.researchgate.net/publication/263278801_Saude_da_mulher_na_refor ma_sanitaria_brasileira>. Acessado em: 15 abr. 2021.

CARVALHO, Marília Pinto de. Gênero e trabalho docente: em busca de um referencial teórico. In: BRUSCHINI, Cristina; BUARQUE DE HOLLANDA, Heloísa (Org.). Horizontes plurais: novos estudos de gênero no Brasil. São Paulo: Editora 34, Fundação Carlos Chagas, 1999.Disponível em: 
$<$ https://www.scielo.br/scielo.php?script=sci_arttext\&pid=S0100$15742000000100011>$. Acessado em: 16 abr. 2021.

COELHO, Edméia de Almeida Cardoso; LUCENA, Maria de Fátima Gomes de; SILVA, Ana Tereza de Medeiros. O planejamento familiar no Brasil no contexto das Políticas públicas de saúde: determinantes históricos.2009. Disponível em: <.http://www.scielo.br/pdf/ean/v13n1/v13n1a21>.Acessado em: 15 abr. 2021.

COELHO, S.; PORTO, Y. F. Saúde da mulher. Belo Horizonte: Coopmed, 2009. Disponível em: $<$ https://www.nescon.medicina.ufmg.br/biblioteca/imagem/1920.pdf > . Acesso em: 15 abr. 2021.

DIAZ, J.; DIAZ. M. Contracepção na adolescência. In: Schor N, Mota MSFT, Branco VC. (Org.). Cadernos: juventude, saúde e desenvolvimento. Brasília: Ministério da Saúde; 1994. Disponível em: < DIAZ, J.; DIAZ. M. Contracepção na adolescência. In: Schor N, Mota MSFT, Branco VC.(Org.). Cadernos: juventude, saúde e desenvolvimento. Brasília: Ministério da Saúde; 1994. >. Acessado em: 15 abr. 2020.

DIAS, Maria Odila Leite da Silva. Teoria e método dos estudos feministas: perspectiva histórica e hermenêntica do cotidiano. In: COSTA, Albertina de Oliveira \& BRUSCHINI, Cristina. Uma Questão de Gênero. Rio de Janeiro: Rosa dos Tempos. São Paulo: Fundação Carlos Chagas, 1992. Disponível em: $<$ http://doczz.com.br/doc/651277/a-perspectiva-de-genero>.Acessado em: 20 jan. 2021.

FREITAS, Giselle Lima de; VASCONCELOS, Camila Teixeira Moreira; MOURA, Escolástica Rejane Ferreira; PINHEIRO, Ana Karina Bezerra. Discutindo a política de atenção à saúde da mulher no contexto da promoção da saúde. Revista Eletrônica de Enfermagem, v. 11, n. 2, 2009. Disponível em: <https://www.fen.ufg.br/revista/v11/n2/v11n2a26.htm>.Acessado em: 13 mai. 2021.

FARIA PENAFORTE, Marta Cristina Lourdes et al. Conhecimento, uso e escolha dos métodos contraceptivos por um grupo de mulheres de uma unidade básica de saúde em Teresópolis, RJ. Cogitare Enfermagem, v. 15, n. 1, 2010. Disponível em: $<$ https://repositorio.ufba.br/ri/bitstream/ri/20776/1/Disserta\%C3\%A7\%C3\%A3o_\%2 0Enf_\%20\%20Sarah\%20Alves\%20Moura\%20Costa.pdf>.Acessado em:13 de jan. 2021.

HEILBORN, Maria Luiza et al. Assistência em contracepção e planejamento reprodutivo na perspectiva de usuárias de três unidades do Sistema Único de Saúde no Estado do Rio de Janeiro, Brasil. Cad saúde pública, v. 25, n. Supl 2, p. S269-S78, 2009. Disponível em: <http://www.scielo.br/scielo. php?pid=S0102311X2009001400009\&script=sci_abstract\&tlng=pt>. Acessado em: 10 mar. 2021.

MERHY, EE. Saúde: a cartografia do trabalho vivo. São Paulo (SP): Hucitec; 2002. Disponível em: <http://www.scielo.br/pdf/csp/v24n8/23.pdf>.Acessado em: 10 março 2021.

MIRANDA-RIBEIRO, Paula et al. Perfis de Vulnerabilidade Feminina ao HIV/aids em Belo Horizonte e Recife: comparando brancas e negras. Saúde e Sociedade, v. 19, n. supl. 2, p. 21-35, 2010. Disponível em: <https://www.revistas.usp.br/sausoc/rt/captureCite/29688/31562>. Acessado em: 13 jan.2021. 
OLIVEIRA, MM; PINTO, IC; COIMBRA, VCC. Potencialidades no atendimento integral: a prevenção do câncer do colo do útero na concepção de usuárias da estratégia saúde da família. Revista Latino-americana de Enfermagem. 2007. Disponível em: <http://www.scielo.org.co/pdf/aven/v31n2/v31n2a07.pdf>. Acessado em: 20 de jan. 2021.

RESSEL, Lúcia Beatriz et al. Exame preventivo do câncer de colo uterino: a percepção das mulheres. Avances enEnfermería, v. 31, n. 2, p. 65-73, 2013. Disponível em:<http://www.scielo.org.co/pdf/aven/v31n2/v31n2a07.pdf $>$.Acessado em 5 de junho de 2021.

SANTOS, Edméa O. A metodologia da webquest interativa na educação online. Tecnologia e educação: as mídias na prática docente. Rio de Janeiro: WAK Editora, v. 1 , 2003. Disponível em: $<$ https://encontrovirtual.files.wordpress.com/2014/03/edmea-artigos.pdf >.Acessado em:13 jun. 2021.

SANTOS, Boaventura de Sousa. Poderá o direito ser emancipatório? Revista crítica de ciências sociais, n. 65, p. 03-76, 2003. Disponível em: $<$ http://www.boaventuradesousasantos.pt/media/pdfs/podera_o_direito_ser_emanci patorio_RCCS65.PDF>. Acessado em: 16 jan. 2021.

SULLEROT, E. Historia y Sociologia del Trabajofemenino. Barcelona: Península, 1988. Disponível em: $<$ https://books.google.com.br/books/about/Historia_y_sociologia_del_trabajo_femeni. html?id=LescvgEACAAJ\&redir_esc=y>. Acessado em: 12 abril 2021.

SILVA, Sed; VASCONCELOS, Ev; SANTANA, Me; LIMA, Vla; CARVALHO, Fl; MAR, Df. Representações sociais de mulheres amazônicas sobre o exame Papanicolau: implicações para a saúde da mulher. Escola Anna Nery, Ver Enferm. 2008. Disponível em:<http://www.scielo.br/pdf/reeusp/v44n3/02.pdf>. Acessado em: 12 abril 2021.

SOUTO, K. M. B. A política de atenção integral à saúde da mulher: uma análise de integralidade e gênero. SER Social, v. 10, n. 22, p. 161-182, jan./jun./2008. Disponível em: <http://periodicos.unb.br/index.php/SER_Social/article/view/17>. Acesso em: 18 mar. 2021.

Recebido em janeiro de 2021. Aprovado em março de 2021. 